\title{
Have "formal investigations" into fishing vessel losses ceased?
}

\author{
M S J REILLY
}

From the Department of Community Medicine, University of Dundee, Ninewells Hospital and Medical School, Dundee DDI 9SY, UK

ABSTRACT Systematic studies of 618 fishing vessel losses between January 1961 and December 1982 have shown a significantly increased incidence of total losses from 1972 onwards. Comparison of mean pre- and post-1972 rates indicated an increase of $120 \%$ from 2.54 to 5.58 losses per 1000 vessels at risk. Parallel examination of the mortality of fishermen from all occupational accidents showed no improvement. For deaths arising from vessel losses alone, the mean crude death rate, for the same periods, increased by $13 \%$. Despite these findings, formal investigations (courts of inquiry) into fishing losses, ordered by the Department of Transport according to specified criteria, decreased in number from about 1975 onwards. The mean number fell by $61 \%$ from 3.1 (1961-71) to 1.2 a year (1972-82). Furthermore, the reduction in the rate of formal investigations into fishing vessel losses $(-84 \% ; p<0.0001)$ was greater than the corresponding reduction $(-61 \% ; p<$ 0.001 ) in United Kingdom merchant vessel investigations and this difference was statistically significant $(\mathrm{p}<0.01)$. During 1972-82 there were 61 fewer fishing investigations than predicted from the rate at which these were ordered during 1961-71. The last took place in 1979. None of the 141 fishing vessel losses between January 1980 and December 1982 proceeded to formal investigation. The possibility that the criteria for ordering formal investigations have not been fulfilled by the circumstances of fishing vessel losses from 1975 onwards is assessed as one explanation for this paradoxical finding of an inverse relation between losses and investigations. The accident investigation and public reporting procedures for aviation accidents should be adopted for marine accidents in general and fishing vessel losses in particular.

A retrospective survey of 516 United Kingdom fishing vessel losses occurring between 1 January 1961 and 31 December 1980 indicated a significantly increased incidence from 1972 onwards. ${ }^{1}$ The mean number of total losses per 1000 commercially registered vessels at risk rose by $105 \%$ from $2 \cdot 54$ (1961-71) to $5 \cdot 21(1972-80)$. Inclusion of a further 102 losses from 1 January 1981 until 31 December 1982 confirms that the originally reported increased incidence was sustained (fig 1).

Parallel investigation of the mortality from occupational accidents to United Kingdom fishermen during the same period (1961-80) showed no improvement in accident mortality experience. ${ }^{2}$ In fact, the mean accident death rate, due to vessel losses alone, increased by $13 \%$ from $0.75 / 1000(1961-71)$ to $0 \cdot 85 / 1000$ (1972-82). Paradoxically, both increases in

Accepted 17 March 1986 vessel losses and in mortality due to vessel loss occurred during the period within which the Fishing Vessels (Safety Provisions) Rules of 1975 were drafted and introduced. ${ }^{3}$

As part of the overall effort to generate and investigate possible explanations for the phenomenon of increased vessel losses, attention was directed, among other sources, towards the expert evidence contained in the published reports of the formal investigations into selected vessel losses. This paper reports on the changing frequency with which formal investigations into fishing vessel losses have been ordered by the Department of Transport (DTp) and compares this experience with that of the United Kingdom merchant shipping fleet.

\section{Investigation of marine losses}

Accident investigation is a fundamental prerequisite 
Fig 1 Incidence of United Kingdom fishing vessel losses, 1961-82.

for accident prevention. Marine transport accidents are no exception.

The law governing such investigations is embodied in the Merchant Shipping Acts of 1894 and $1970 .{ }^{4}$ The 1970 Act requires that the owner or master (skipper) of a United Kingdom ship reports a casualty to the department by completing a form. The Act defines a "casualty" as:

" $(a)$ the loss or presumed loss, stranding, grounding, abandonment of or damage to a ship; or

(b) a loss of life caused by fire on board or by any accident to a ship or ship's boat, or by any accident occurring on board a ship or ship's boat; or

(c) any damage caused by a ship;

and at the time it occurred, the ship was registered in the United Kingdom or the ship or boat was in the United Kingdom or in the territorial waters thereof."

The official terminology concerning vessel losses is slightly confusing. In general, the term "casualty," as defined in the Act, embraces the operational terms "total loss" and "serious casualty" as used by the DTp. A "serious casualty" is synonymous with major damage or serious financial loss in relation to the size and value of the vessel.

The following summary of the procedure for the investigation of marine casualties (including fishing vessels) is based on an informal paper prepared by the Marine Directorate of the DTp (personal communication). The Marine Directorate has the statutory obligation to conduct such inquiries.

On receipt of a casualty report, the action taken by the DTp (fig 2) is guided as follows:

STAGE 1: MASTER'S REPORT AND/OR SURVEYOR'S REPORT AND/OR WITNESS DEPOSITIONS

For minor incidents - for example, quay contactsthe completion of the master's form may prove adequate. Where the circumstances, although not serious, suggest a need for further information, a DTp

Fig 2 Stages in investigation of marine losses.

surveyor is asked to report. Where the DTp thinks it would be helpful to have statements from those best able to describe the casualty, an officer is authorised to take depositions.

For more serious casualties, or where the sur- $\frac{\mathscr{Q}}{\mathbb{Q}}$ veyor's investigations or depositions show the casu- $\stackrel{2}{\Rightarrow}$ alty to be more serious than at first thought, a DTp응 surveyor is appointed to conduct a "preliminary inquiry."

\section{STAGE 2: PRELIMINARY INQUIRY}

A preliminary inquiry involves a thorough? investigation into all aspects of the casualty. It may cover a relatively simple chain of sequential events or it may extend to matters involving consultation with a variety of interests. When all inquiries and consultations are completed, a confidential report is pre-음 pared to enable the DTp to decide what further $>$ action, if any, is required. Should the report suggest? that it would be appropriate for a public inquiry to ben held then a so called "formal investigation" is" ordered.

STAGE 3: FORMAL INVESTIGATION In deciding whether a private preliminary inquirye should proceed to a public formal investigation, the ${ }_{\varnothing}$ following criteria are considered but, according to the $\stackrel{?}{+}$ DTp, are not decisive:

(a) whether lives have been lost;

(b) whether the casualty has given rise to serious public concern; 
(c) whether it is desirable for the cause of the casualty to be more clearly established;

(d) whether it seems likely that there are lessons to be learnt from the casualty;

(e) whether the circumstances call for strong disciplinary action to be taken against the master or any member of the crew.

Courts of formal investigation are presided over by a wreck commissioner (in England, Wales, and Northern Ireland) or by a sheriff (in Scotland). Each is assisted by one or more assessors of nautical, engineering, or other skill or knowledge depending on the circumstances of the casualty. ${ }^{4}$ At the conclusion of the formal investigation a report is submitted to the DTp for subsequent publication. Each assessor must either sign the report or dissent from it by giving his reasons for doing so.

\section{Methods}

With the assistance of the Marine Directorate, every fishing and merchant vessel loss between 1961 and 1982 which proceeded to a formal investigation was traced and abstracted from departmental records. Each record identified the vessel's name, the dates of loss and investigation, and the cause of vessel loss.

The methods used for determining the annual incidence and causes of total losses throughout this period have been described elsewhere. ${ }^{1}$ Merchant vessel loss rates include vessels exceeding 100 tons only.
The formal investigation rate is defined as the annual number of total losses which proceed to formal investigation expressed as a proportion $(\%)$ of all total losses in that year. The cause specific formal investigation rate, however, includes the combined numbers of total losses and serious casualties because the numbers of losses and casualties by cause could not be identified separately from pre-1968 records.

The predicted numbers of formal investigations between 1972 and 1982, assuming that these were ordered at a rate commensurate with that for 1961-71, were derived by applying the 1961-71 rate $(17 \cdot 3 \%)$ to the number of total losses a year.

Differences between the proportions of fishing and merchant vessel losses proceeding to formal investigation were assessed for statistical significance using the chi-square test.

\section{Results}

A complete list of the 46 United Kingdom fishing vessel losses which became the subject of DTp formal investigations between January 1961 and December 1982 is provided in table 1 . There were 56 merchant shipping investigations during this period.

Total losses as well as formal investigations and the formal investigation rate are depicted graphically in fig 3. Since 1976, the rate of formal investigations into merchant losses, apart from those years in which none was ordered, has tended to increase. For the years
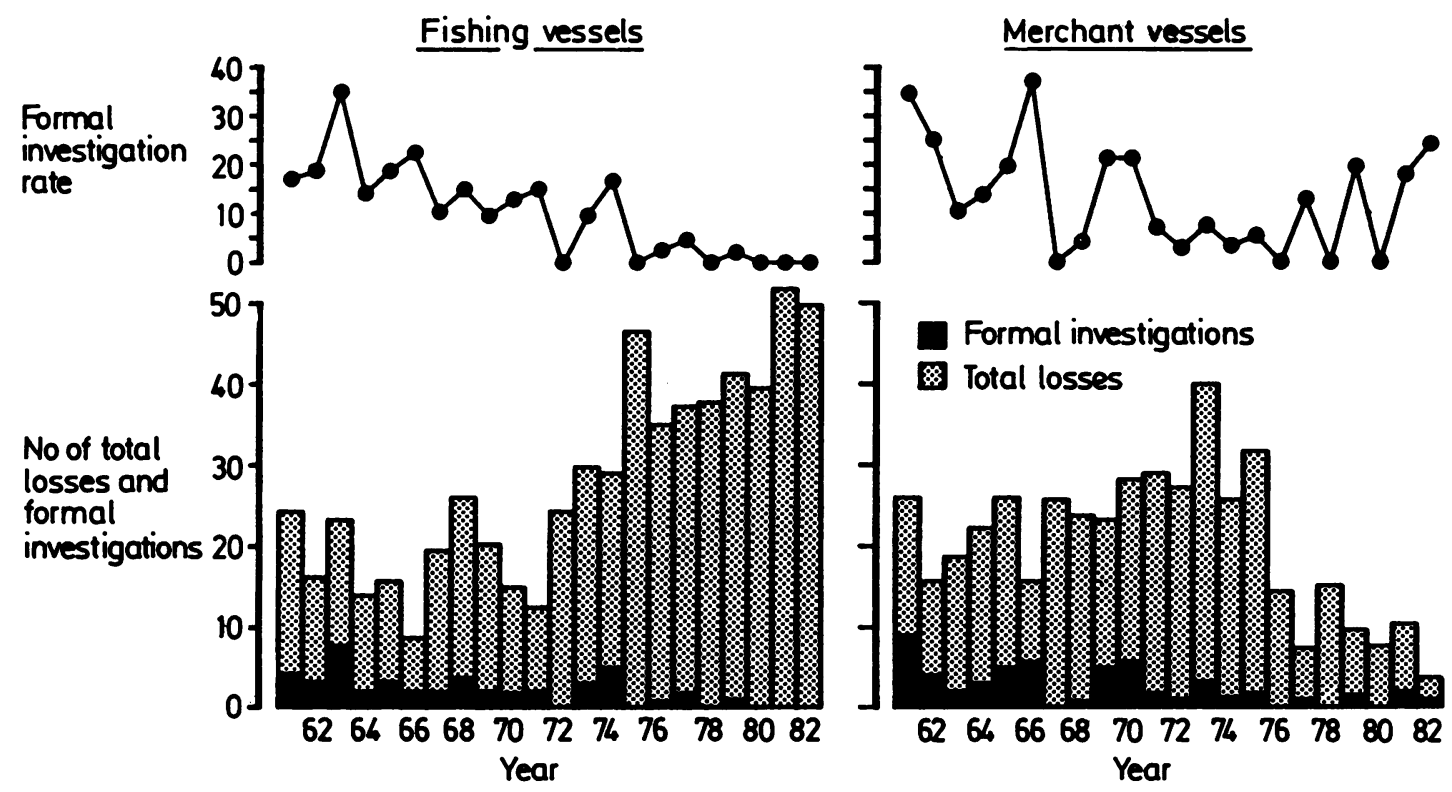

Fig 3 Comparison of formal investigation rates for United Kingdom fishing and merchant vessel losses, $1961-82$. 
Table 1 Formal investigations into fishing vessel losses, 1961-82. (Figure in parentheses indicates year of formal investigation if different from year of casualty)

\begin{tabular}{|c|c|c|c|}
\hline Vessel name & & Date of loss & Cause of loss \\
\hline 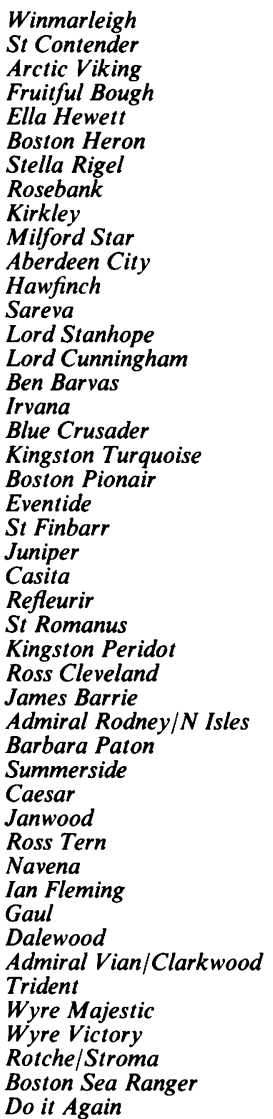 & $\begin{array}{l}1969 \\
1970 \\
1971 \\
1973\end{array}$ & $\begin{array}{l}03 / 01 / 61 \\
12 / 04 / 61 \\
18 / 10 / 61(62) \\
09 / 12 / 61(62) \\
02 / 11 / 62(63) \\
03 / 12 / 62(63) \\
21 / 12 / 62(63) \\
24 / 01 / 63 \\
08 / 04 / 63(64) \\
02 / 08 / 63(64) \\
16 / 09 / 63(64) \\
19 / 09 / 63(64) \\
13 / 10 / 63(64) \\
07 / 11 / 63(64) \\
20 / 12 / 63(64) \\
03 / 01 / 64 \\
23 / 03 / 64 \\
13 / 01 / 65 \\
25 / 01 / 65 \\
14 / 02 / 65 \\
04 / 08 / 66(67) \\
27 / 12 / 66(67) \\
19 / 02 / 67 \\
15 / 06 / 67(68) \\
03 / 01 / 68 \\
11 / 01 / 68 \\
26 / 01 / 68 \\
04 / 02 / 68 \\
29 / 03 / 69 \\
21 / 06 / 69(70) \\
05 / 02 / 70(71) \\
06 / 05 / 70(72) \\
21 / 04 / 71(72) \\
29 / 10 / 71(73) \\
09 / 02 / 73(73) \\
06 / 12 / 73(74) \\
25 / 12 / 73(75) \\
08 / 02 / 74 \\
03 / 03 / 74(75) \\
07 / 03 / 74(75) \\
03 / 10 / 74(75) \\
18 / 10 / 74(75) \\
14 / 01 / 76 \\
08 / 07 / 77(78) \\
05 / 12 / 77(79) \\
20 / 01 / 79\end{array}$ & $\begin{array}{l}\text { Stranding } \\
\text { Stranding } \\
\text { Foundering } \\
\text { Stranding } \\
\text { Stranding } \\
\text { Stranding } \\
\text { Stranding } \\
\text { Foundering } \\
\text { Stranding } \\
\text { Stranding } \\
\text { Stranding } \\
\text { Stranding } \\
\text { Missing } \\
\text { Stranding } \\
\text { Stranding } \\
\text { Stranding } \\
\text { Stranding } \\
\text { Missing } \\
\text { Stranding } \\
\text { Missing } \\
\text { Foundering } \\
\text { Foundering } \\
\text { Stranding } \\
\text { Fire/explosion } \\
\text { Foundering } \\
\text { Missing } \\
\text { Missing } \\
\text { Capsize } \\
\text { Stranding } \\
\text { Collision } \\
\text { Stranding } \\
\text { Stranding } \\
\text { Stranding } \\
\text { Stranding } \\
\text { Stranding } \\
\text { Stranding } \\
\text { Stranding } \\
\text { Missing } \\
\text { Stranding } \\
\text { Collision } \\
\text { Missing } \\
\text { Stranding } \\
\text { Foundering } \\
\text { Collision } \\
\text { Foundering } \\
\text { Foundering }\end{array}$ \\
\hline
\end{tabular}

Stranding = Grounding on coastline, rock outcrop, or sand bank.

Foundering $=$ Loss of watertight integrity.

1980-2 inclusive, three of the 23 merchant losses $(13 \%)$ proceeded to formal investigation whereas none of the 141 fishing vessel losses, which occurred during the same period, did so.

Summary statistics relating to total losses and formal investigations for the periods 1961-71, 1972-82, and for both combined, are presented in table 2. Fishing vessel losses increased both in absolute and relative-values. For all merchant shipping losses there was an absolute decline in losses but for vessels exceeding 100 tons only there was a relative increase. Formal investigations decreased both absolutely and relatively for fishing as well as for merchant vessel losses. The reduction in the rate of formal investigations into fishing vessel losses $(-81 \% ; p<0.0001)$ was greater than the corresponding reduction $(-61 \% ; p<$ 을 0.001 ) in merchant vessel investigations and the difference between these was statistically significant ( $p^{\text {G }}$ $<0.01$ ).

Although the rates of investigation into fishing and $\mathbb{\omega}^{N}$ merchant shipping losses exhibit no statistically 0 significant difference during 1961-71, a significantly ${ }_{\bullet}$ greater proportion $(\mathrm{p}<0.03)$ of merchant losses than fishing losses proceeded to formal investigation dur- $\stackrel{?}{?}$ ing 1972-82.

Table 3 shows a summary of the changes in mean 0 numbers and rates of total loss and formal investigation between 1961-71 and 1972-82. 
Table 2 Total losses and formal investigations - a comparison of United Kingdom fishing and merchant shipping experience, $1961-82$

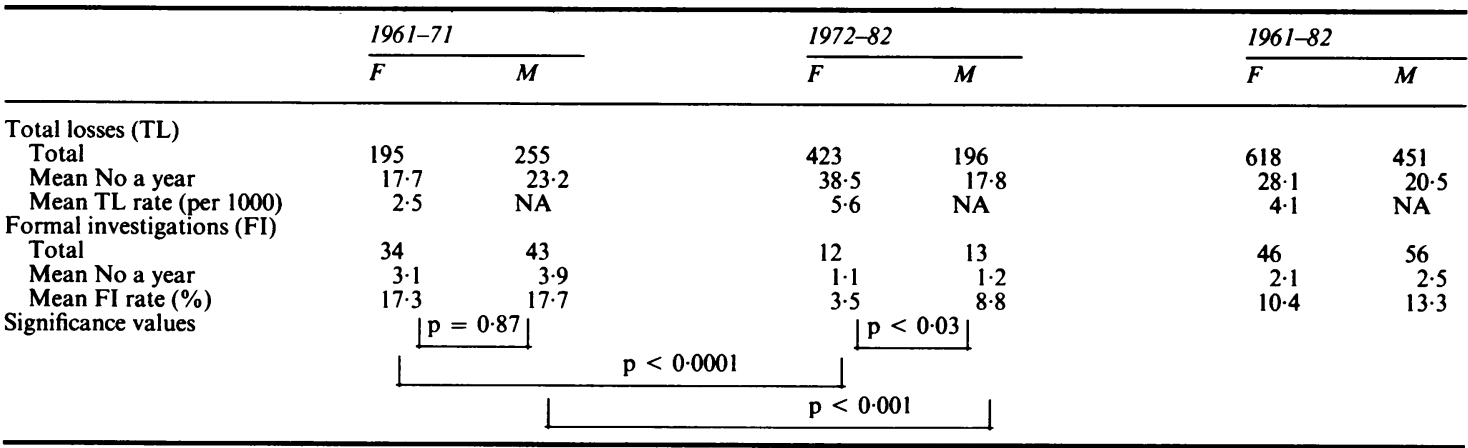

F - Fishing vessel group.

M - Merchant vessel group.

NA - Not available. The total number of all merchant vessels at risk is not known. For merchant vessels $>100$ tons, the loss rates (per 1000 at risk) are 2.3 (1961-71); 3.2 (1972-82); and 2.8 (1961-82).

Significance values refer to between group differences and within group/between time period differences in the proportions of total losses proceeding to formal investigation.

Table 3 Changes in mean total losses and rate of formal investigations between 1961-71 and 1972-82

\begin{tabular}{|c|c|c|}
\hline & Fishing vessels & Merchant vessels \\
\hline \multicolumn{3}{|c|}{ Total losses } \\
\hline $\begin{array}{l}\text { No } \\
\text { Rate }\end{array}$ & $\begin{array}{l}+118 \% \\
+120 \% \\
0<0.0001\end{array}$ & $\overline{N A}^{23 \%}$ \\
\hline \multicolumn{3}{|c|}{ Formal investigations } \\
\hline Rate & $\begin{array}{l}-84 \% \\
\mathrm{p}<0.0001\end{array}$ & $\begin{array}{l}-61 \% \\
p<0.001\end{array}$ \\
\hline
\end{tabular}

Table 4 shows the cause specific formal investigation rates. The overall rate is $5.5 \%$ but this varies from a nil rate (for "other" causes of loss) to $26.9 \%$ (for "missing" vessels). Investigations into founderings, which constitute the largest cause of vessel loss and claim the second highest number of lives, amounted to $2 \cdot 7 \%$.

Predicted numbers of formal investigations for
1972-82 are compared with actual numbers for that period in table 5 .

Table 5 Comparison of predicted $(P)$ and actual $(A)$ formal investigations into fishing vessel losses, 1972-82

\begin{tabular}{|c|c|c|c|c|}
\hline \multirow[b]{2}{*}{ Year } & \multirow{2}{*}{$\begin{array}{l}\text { Total } \\
\text { No of } \\
\text { losses }\end{array}$} & \multicolumn{2}{|c|}{ Formal investigations } & \multirow{2}{*}{$\begin{array}{l}\text { Difference } \\
(A)-(P)\end{array}$} \\
\hline & & $(P)^{*}$ & (A) & \\
\hline 1972 & 24 & 4 & 0 & -4 \\
\hline 1973 & 30 & 5 & 3 & - \\
\hline 1974 & 29 & 5 & 5 & 0 \\
\hline 1975 & 47 & 8 & 0 & - \\
\hline 1976 & 35 & 6 & 1 & - \\
\hline 1977 & 37 & 6 & 2 & - \\
\hline 1978 & 38 & 7 & 0 & - \\
\hline 1979 & 42 & 7 & 1 & -6 \\
\hline 1980 & 39 & 7 & 0 & - \\
\hline 1981 & 52 & 9 & 0 & -9 \\
\hline 1982 & 50 & 9 & 0 & -9 \\
\hline Total & 423 & 73 & 12 & -61 \\
\hline
\end{tabular}

*Predicted values (rounded to nearest whole number) were derived by applying the $1961-71$ rate $(17 \cdot 3 \%)$ to the number of total losses a year.

Table 4 Cause specific formal investigation rates, United Kingdom fishing vessels, 1961-82

\section{Formal investigations}

\begin{tabular}{llrrr} 
& & No & Rate (\%) & Lives lost \\
\cline { 3 - 5 } Cause of vessel loss & TL and SC & 8 & $2 \cdot 7$ & 96 \\
\hline Foundering & 299 & 26 & $12 \cdot 4$ & 24 \\
Stranding & 209 & 3 & $2 \cdot 4$ & 20 \\
Collision & 126 & 1 & $26 \cdot 0$ & 52 \\
Fire/explosion & 99 & 7 & $4 \cdot 0$ & 0 \\
Missing & 26 & 1 & $0 \cdot 0$ & 7 \\
Capsize & 25 & 0 & $5 \cdot 5$ & 370 \\
Other & 48 & 46 & & 0 \\
Total & 832 & & & \\
\hline
\end{tabular}

$\mathrm{TL}$ and $\mathrm{SC}=\mathrm{Total}$ losses and serious casualties.

Foundering $=$ Loss of watertight integrity. 


\section{Discussion}

Formal investigations into fishing vessel losses have declined both in absolute and relative terms at least since 1975. The Department of Transport (formerly Trade) has ordered no formal investigations since 1979. None is planned. The reasons, however, are unclear. One possible explanation is that the criteria for ordering formal investigations have not been fulfilled by the circumstances of losses from about 1975 onwards.

If the answer to all of the following questions, each implicit in the respective criteria, is "no," then this hypothesis is tenable.

HA VE LIVES BEEN LOST?

Between 1972 and 1982, 193 lives were lost owing to vessel losses alone. Of these, $62(32 \%)$ occurred in various losses during those years for which no formal investigations were ordered at all - that is, 1972, 1975, 1978 , and 1980-2 inclusive.

\section{HA VE CASUALTIES TO VESSELS GIVEN RISE TO SERIOUS PUBLIC CONCERN?}

If Parliamentary activity (questions and statements) together with responsible media reports and commentaries are acceptable surrogate measures of "serious public concern," then many vessel losses have given rise to such concern. Obvious examples are the losses of "Tarradale II" (7 dead) $)^{5}$; "Carinthia" (6 dead) ${ }^{6}$; "Ocean Monarch" (7 dead) ${ }^{7}$; and "Celerity" $(6 \text { dead })^{8}$

\section{IS IT DESIRABLE FOR THE CAUSE OF THE CASUALTIES TO BE MORE CLEARLY ESTABLISHED?}

It is difficult to conceive of circumstances, particularly when lives have been lost, where it is not desirable for the cause of vessel loss to be more clearly established. Without determining how an accident occurred and, furthermore, understanding how someone died and why, strategies for effective prevention are seriously weakened. ${ }^{9}$

\section{IS IT LIKELY THAT THERE ARE LESSONS TO BE LEARNT FROM (INVESTIGATION OF) THE CASU A L TIES?}

If the circumstances of every vessel loss can be regarded as unique (if only in time or in space) then from each loss there exists the potential for deriving evidence of possible relevance to the prevention of further similar types of accident. Indeed, this tenet guides the whole rationale of accident investigation. ${ }^{10}$ To suggest that fewer insights were to be gained from investigating vessel losses in the 1970s, compared with those in the 1960s, does not appear to be particularly realistic. That nothing at all was to be gained from formally investigating any of the 141 losses during 1980-2 appears unlikely.

DO THE CIRCUMSTANCES CALL FOR

DISCIPLINARY ACTION TO BE TAKEN AGAINST

THE MASTER OR ANY MEMBER OF THE CREW?

The desirability of using a formal investigation for the purposes of disciplinary action of whatever severity is $\mathrm{c}$ debateable except in cases of obvious extreme negli- $\overrightarrow{0}$

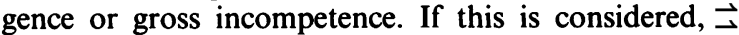
however, to be a bona fide purpose of accident $\stackrel{\sigma}{\omega}$ investigation into vessel losses then it raises the ques- $O$ tion as to whether acts of omission or commission, which might invoke disciplinary action, were less frequent in the 1970s than the 1960s and apparently nonexistent from 1980 to 1982.

In summary, it seems unlikely, given an increased 음 number as well as an increased incidence of vessel losses, that recent fishing vessel losses have not ${ }_{d}$ fulfilled at least one, and often more or occasionally all, of the DTp criteria. Therefore, this hypothesis can probably be discounted.

In response to the question "Have formal $\vec{\varnothing}$ investigations into fishing vessel losses ceased?" the .v answer is yes. For fishing vessel losses occurring between February 1979 and July 1985, no formal investigations were ordered thus making this the longest continuous interval in the past 25 years without such an investigation. But whether this cessation is $\mathbb{Q}$ temporary or permanent is not known. One possible $\overrightarrow{\vec{Q}}$ explanation has been proposed, assessed, and discounted as being unlikely. There are other possible explanations such as the potentially high costs involved in investigating escalating numbers of vessel losses or the impossibility of increasing the $\mathbb{D}$ investigative workload of existing DTp staff. For instance, in response to a recent parliamentary question, the Secretary of State for Transport stated that "... information about the causes and recommendations (from the investigations of 424 losses between 1975 and 1984) and the subsequent actions by DTp is not readily available and could be provided only at $\frac{7}{O}$ disproportionate cost and effort."11

Of the 265 fishing boats lost between February $\mathrm{N}$ 1979 and December 1984 (and a further unpublished number to July 1985), in each case the DTp considered that, "... the cause of the casualty had been $\omega$ clearly established and that a formal investigation would not produce any further information ..." (personal communication).

The consequences of declining to investigate these accidents through the process of formal investigation is difficult to gauge. It is also difficult, however, to accept that the long term effects will be anything other than detrimental to the safety of fishermen. It might 
well be argued that formal investigations are not the best way of analysing the circumstances of fishing boat losses but, given the practice of the DTp not to publish in full the findings of preliminary inquiries (apparently because they contain confidential information), the formal investigation procedure must surely be regarded as desirable in the absence of any other adequate means of disseminating information of relevance to the prevention of potentially similar losses. ${ }^{12}$ It is questionable whether the intermittent use of Merchant Shipping Notices (M Notices) alone is entirely satisfactory as a vehicle for effective prevention.

In passing, it ought to be noted that the question of confidentiality certainly does not appear to be an obstacle to the publication of rigorous and detailed examinations of aircraft accidents (by another branch of DTp) either in periodic aircraft accident reports or regular safety bulletins. Indeed, it is possible that the widespread availability of these air safety reports might be one of the factors which has contributed to a heightened awareness of aviation safety as well as to the reduction in aircraft accidents.

Since it has now become clear that the safety record of the fishing industry has shown no consistent tendency to improve in recent years and in one respect, at least, has worsened significantly, the observation of an unexplained absolute and relative decline in DTp formal investigations must be of fundamental concern to everyone connected with the safety of fishermen at work. The search for an explanation for this paradoxical observation presents an important challenge.

In the absence of public examination or reporting of the causes and circumstances of fishing vessel losses, the Marine Directorate ought to adopt a model for the investigation and public reporting of marine accidents comparable with that used by the aircraft Accidents Investigation Branch (of the same department) in the aftermath of aviation accidents. ${ }^{13}$
I am grateful to Miss Jean Wrench (Marine Directorate) and $\mathrm{K}$ A Lewis (Marine Library) of the Department of Transport for their help. In the Department of Community Medicine Professors Charles Florey and Alex Mair, Dr Owen Lloyd, Dr Melody Lloyd, and Mrs Fiona Williams offered constructive criticisms of earlier drafts. Mr Simon Ogston provided statistical advice.

Financial support for this research was provided by the University of Dundee.

\section{References}

1 Reilly MSJ. The safety of UK fishing vessels, 1961-80. Journal of Navigation 1984;37:60-82.

2 Reilly MSJ. Mortality from occupational accidents to UK fishermen, 1961-80. Br J Ind Med 1985;42: 806-14.

3 Fishing vessels (safety provisions) rules, 1975. London: HMSO, 1975.

4 Thomas M, Steel D. The merchant shipping acts. In: Hewson B, ed. British shipping laws. Vol 11. 7th ed. London: Stevens and Sons, 1976.

5 Official report of Commons debates, 5th series; 962: 788-93.

6 Official report of Commons debates, 5th series; 969: 777-8.

7 Official report of Commons debates, 5th series; 976: 29-34.

8 Official report of Commons debates, 6th series; 1:429-31.

9 Hale AR. Accident investigation: collecting the facts? Occupational Health 1977;29:400-3.

10 Hale AR. Accident investigation systems. Occupational Health 1975;27:110-3.

11 Official report of Commons debates, 6th series; 91:161-2.

12 Cockcroft AN. Marine inquiries and their impact on safety. Proceedings of the Institute of Marine Engineers and Nautical Institute seminar on marine inquiries and casualty investigations, London, 23rd November 1982. London: The Nautical Institute, 1982, 61-6.

13 Civil Aviation. (Investigation of Accidents) Regulations 1983. London: HMSO, 1983. (SI 1983 No 551.) 